\title{
Mela em Melancia Causada por Rhizoctonia solani AG1-IA em Roraima
}

\author{
Kátia de L. Nechet \& Bernardo A. Halfeld-Vieira \\ Embrapa Roraima, BR 174, km 08, Cx. Postal 133, CEP 69301-970, Boa Vista, RR, e-mail: katia@cpafrr.embrapa.br
}

(Aceito para publicação em 13/06/2005)

Autor para correspondência: Kátia de Lima Nechet

\begin{abstract}
Web blight on watermelon caused by Rhizoctonia solani AG1-IA in Roraima, Brazil

Web blight was observed on leaves and fruits of watermelon in Boa Vista, Roraima, Brazil. An isolate of Rhizoctonia

solani (=Thanatephorus cucumeris) was anastomosed with the tester strain of AG1-IA.
\end{abstract}

A melancia [Citrullus lanatus (Thunb) Matsum \& Nakai] é a principal cucurbitácea cultivada no Estado de Roraima, constituindo importante fonte de renda para os produtores locais. Em setembro de 2004, o Laboratório de Fitossanidade da Embrapa Roraima recebeu amostras de folhas e frutos de melancia provenientes do município de Mucajaí com manchas negras com aspecto apodrecido, de grandes dimensões e formato irregular (Figuras 1A e 1B). Em microscópio estereoscópico observaram-se freqüentemente hifas grossas associadas às manchas. Após observações em microscópio ótico o agente causal foi identificado como Rhizoctonia solani Kühn (Sneh. Identification of Rhizoctonia Species. 1991). A partir de fragmentos do tecido foliar das amostras com sintoma da doença foi feito o isolamento do fungo. A colônia de coloração bege claro apresentou crescimento micelial rápido à $25^{\circ} \mathrm{C}$, em ausência de luz (4,5 cm.24 h-1) e formação de microescleródios (113$238 \mu \mathrm{m}$ ), inicialmente brancos tornando-se escuros (Figura 1C). Para o teste de patogenicidade, o fungo foi transferido para placas de Petri contendo meio batata-dextrose-agar (BDA), permanecendo em incubadora nas mesmas condições descritas anteriormente. Após dez dias, retiraram-se discos de micélio de $5 \mathrm{~mm}$ da periferia destas colônias que foram colocadas na superfície de folhas de melancia em cinco plantas no estádio de frutificação. Como controle foram utilizados discos de BDA. As folhas inoculadas foram mantidas em câmara úmida por $24 \mathrm{~h}$ em temperatura ambiente. Após sete dias, os sintomas de mela foram observados nas folhas inoculadas. O patógeno $R$. solani foi reisolado, completando-se o postulado de Koch. A determinação do grupamento de anastomose foi feita utilizando-se a técnica da lâmina de vidro para microscopia (Ceresini et al., Summa Phytopathologica 22:145. 1996). Os isolados padrões utilizados foram AG1-IA; AG1-IB; AG-
2 IIIB; AG3 (ST9, ST11-6); AG4 (AHI, 140); AG7-H0; AGBI (TS-2-4). Após 24 h foi observada a anastomose de hifas em microscópio ótico utilizando solução de safranina-O $0,03 \%+\mathrm{KOH} 3 \%$. A reação de anastomose do isolado de melancia com o padrão AG1-IA foi considerada positiva por ter sido observado o contato de hifas, fusão da parede celular e morte de células adjacentes (Parmeter et al., Phytopathology 59:1270. 1969).

Agradecimento: os autores agradecem ao Dr. Silvaldo Felipe da Silveira, da Universidade Estadual do Norte Fluminense, pelo envio dos isolados padrões de Rhizoctonia solani.

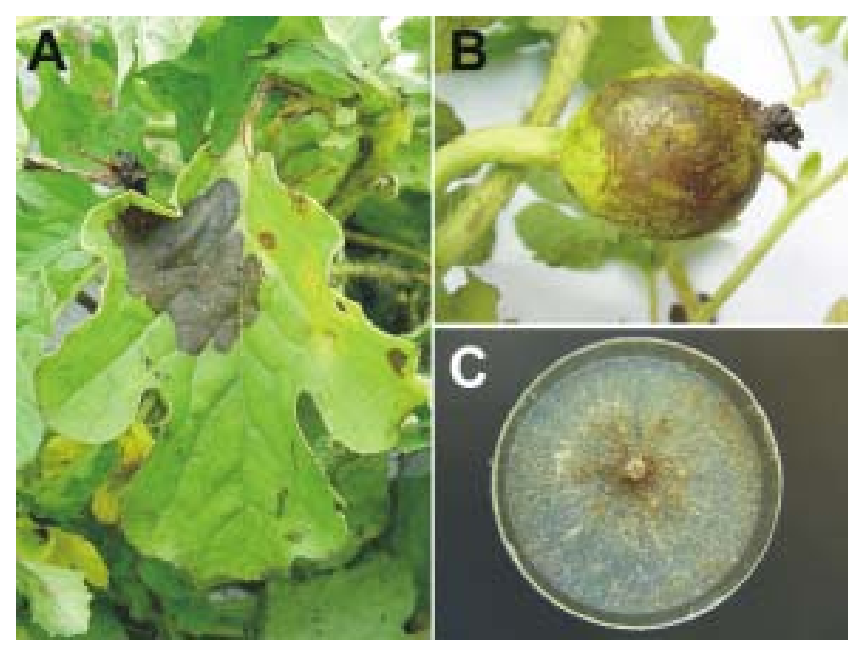

FIG. 1- A- Sintomas da mela em folha (A) e fruto (B) de Citrullus lanatus e colônia (C) de Rhizoctonia solani em meio BDA, com microescleródios. 